\title{
Mig-6 Gene Knockout Induces Neointimal Hyperplasia in the Vascular Smooth Muscle Cell
}

\author{
Ju Hee Lee, ${ }^{1}$ Sorim Choung, ${ }^{1}$ Ji Min Kim, ${ }^{1}$ Jung Uee Lee, ${ }^{2}$ Koon Soon Kim, ${ }^{1}$ Hyun Jin Kim, ${ }^{1}$ \\ Jae-Wook Jeong, ${ }^{3}$ and Bon Jeong $\mathrm{Ku}^{1}$ \\ ${ }^{1}$ Department of Internal Medicine, Chungnam National University School of Medicine, 282 Munhwa-ro, Jung-gu, \\ Daejeon 301-721, Republic of Korea \\ ${ }^{2}$ Department of Pathology, Daejeon St. Mary's Hospital, College of Medicine, The Catholic University of Korea, \\ 222 Banpo-daero, Seocho-gu, Seoul 137-701, Republic of Korea \\ ${ }^{3}$ Department of Obstetrics, Gynecology \& Reproductive Biology, Michigan State University, Grand Rapids, MI 49530, USA
}

Correspondence should be addressed to Bon Jeong Ku; bonjeong@cnu.ac.kr

Received 4 September 2014; Revised 25 November 2014; Accepted 25 November 2014; Published 10 December 2014

Academic Editor: Giuseppe Murdaca

Copyright (C) $2014 \mathrm{Ju}$ Hee Lee et al. This is an open access article distributed under the Creative Commons Attribution License, which permits unrestricted use, distribution, and reproduction in any medium, provided the original work is properly cited.

\begin{abstract}
Although advances in vascular interventions can reduce the mortality associated with cardiovascular disease, neointimal hyperplasia remains a clinically significant obstacle limiting the success of current interventions. Identification of signaling pathways involved in migration and proliferation of vascular smooth muscle cells (SMCs) is an important approach for the development of modalities to combat this disease. Herein we investigate the role of an immediate early response gene, mitogeninducible gene-6 (Mig-6), in the development of neointimal hyperplasia using vascular smooth muscle specific Mig-6 knockout mice. We induced endoluminal injury to one side of femoral artery by balloon dilatation in both Mig- 6 knockout and control mice. Four weeks following injury, the artery of Mig- 6 knockout mice demonstrated a 5.3-fold increase in the neointima/media ratio compared with control mice $(P=0.04)$. In addition, Mig- 6 knockout vascular SMCs displayed an increase in both cell migration and proliferation compared with wild-type SMCs. Taken together, our data suggest that Mig-6 plays a critical role in the development of atherosclerosis. This finding provides new insight into the development of more effective ways to treat and prevent neointimal hyperplasia, particularly in-stent restenosis after percutaneous vascular intervention.
\end{abstract}

\section{Introduction}

Atherosclerosis remains a leading cause of death and morbidity in developed countries. It is a disease that affects the circulatory system and has distinct clinical manifestations that depend on the particular circulatory bed affected. For example, atherosclerosis of the coronary arteries causes myocardial infarction and angina pectoris. Percutaneous vascular intervention is commonly performed for the treatment of symptomatic atherosclerosis. However, recurrent lumen narrowing occurs in $3-20 \%$ of patients despite the introduction of a drug-eluting stent. This limitation presents a clinically significant obstacle responsible for reducing the long-term success of current interventions [1].

Vascular smooth muscle cells (SMCs) are involved in lesion progression, which is responsible for the pathogenesis resulting from atherosclerosis [2]. As part of the vascular response to injury, SMCs migrate from the media, across the intima, into the lumen of the vessel where they proliferate and synthesize cytokines, consequently sustaining the progression of intimal hyperplasia [3-5]. Intimal hyperplasia, in response to mechanical and immunologic insults, is one of the main pathophysiological consequences of postvascular intervention restenosis [5-8]. Therefore, the identification of signaling pathways involved in the migration and proliferation of SMCs during intimal hyperplasia is critical for the development of modalities to combat this disease.

Mitogen-inducible gene-6 (Mig-6) is an immediate early response gene that can be induced by various mitogens, stresses, and hormones [9-12]. Mig-6 can interact directly with all four members of the ErbB family, including epidermal growth factor receptor (EGFR) and ErbB2-4, to act as 
a negative feedback regulator of the ErbB receptor tyrosine kinase pathway [10, 13-15]. Ablation of Mig-6 in mice leads to the development of epithelial hyperplasia, adenoma, and adenocarcinoma in organs such as the lung, gallbladder, and bile duct [16]. It is well documented as a tumor suppressor gene $[12,16-21]$ and was recently reported to be involved in cholesterol homeostasis and bile acid synthesis [22]. EGFR is also expressed by vascular SMCs $[23,24]$, and ligands of EGFR induced cellular proliferation and enhanced migration of vascular SMCs [25-27]. However, the role of Mig-6 in vascular SMCs has not been evaluated to date.

In this report we investigated the function of MIG-6 in vascular SMCs and its potential role in the development of atherosclerosis and neointima formation. Using a vascular SMC-specific Mig-6 conditional knockout mouse in an in vivo model of endoluminal injury, together with in vitro SMC cell migration and proliferation assays using small interfering RNA- (siRNA-) mediated Mig-6 knockdown, we demonstrated a significant effect on SMC migration and proliferation.

\section{Materials and Methods}

2.1. Animals. Floxed Mig-6 (Mig- $6^{\text {flox/flox }}$ ) mice were generated as described previously [28]. Transgelin-Cre transgenic mice (C57BL/6J) were kindly provided by Dr. Lee from the Korea Research Institute of Bioscience and Biotechnology. Mice were maintained in a controlled environment $(12 \mathrm{~h}$ light/12 h dark cycle, humidity 50-60\%, ambient temperature $23^{\circ} \mathrm{C} \pm 1^{\circ} \mathrm{C}$ ) and fed ad libitum. All animal experiments were performed in the animal care facility at the Chungnam National University School of Medicine according to the institutional guidelines for the care and use of laboratory animals. Experimental protocols were approved by the institutional review board of Chungnam National University School of Medicine.

2.2. Primary Culture of Vascular Smooth Muscle Cells. Aortas from wild-type and knockout mice were minced and incubated at $37^{\circ} \mathrm{C}$ in Dulbecco's Modified Eagle's Medium (DMEM). The endothelia and adventitia were stripped away, and then the adventitia-free aorta was cut into $3-5 \mathrm{~mm}$ segments. The tissue was incubated for an additional 24 hours in DMEM containing 50\% fetal bovine serum (FBS) to isolate SMCs. Cells were further cultured in DMEM containing $10 \%$ FBS.

2.3. Cell Migration Assay. The transwell migration assay was performed to quantify vascular SMC chemotaxis. A 24-well transwell apparatus (Costar, Corning, NY, USA) was used, with each well containing a $6.5 \mathrm{~mm}$ polycarbonate membrane with $0.8 \mu \mathrm{m}$ pores and coated with $0.1 \%$ gelatin. Vascular SMCs were incubated in serum-reduced medium for 24 hours. The cells were trypsinized, resuspended, and plated. The bottom chamber was filled with DMEM containing 0.1\% FBS and the indicated chemotactic agent. The chamber was incubated for $1-4$ hours at $37^{\circ} \mathrm{C}$ in a $\mathrm{CO}_{2}$ incubator. The membranes were fixed, and the attached cells were stained.
The number of cells that had migrated across the membrane was quantified as the number of cells per low-power microscopic field.

2.4. Cell Proliferation Assay. For proliferation assays, cells grown to $70 \%$ confluence were serum-starved in $0.1 \%$ FBS medium for 24 hours and then seeded onto a 96-well plate. Cells were treated with chemotactic agent in DMEM containing $0.1 \%$ FBS and incubated for $1-4$ hours at $37^{\circ} \mathrm{C}$ in a $\mathrm{CO}_{2}$ incubator. After changing the media, a solution from the cell counting kit-8 (Dojindo, Kumamoto, Japan) was added to the cells. After 2 hours, the absorbance at $450 \mathrm{~nm}$ was measured using an Emax Precision Microplate Reader (Molecular Devices, Sunnyvale, CA, USA).

2.5. Small Interfering RNA Experiments. For siRNA transfection, human vascular SMCs were incubated with CSC complete recombinant serum-free medium and transfected with nonspecific siRNA and Mig-6 siRNA using RNAiMAX (Invitrogen, Carlsbad, CA, USA) following the manufacturer's protocol. After 4 hours, the medium was changed, and cells were incubated for a further 48 hours.

2.6. Surgical Procedure. Endoluminal injury to the femoral artery was produced using a $0.25 \mathrm{~mm}$ diameter balloon angioplasty guidewire (Advanced Cardiovascular Systems, Santa Clara, CA). The animals were anesthetized by intraperitoneal pentobarbital sodium injection (Nembutal, Abbott Laboratories, Chicago, USA), $50 \mathrm{mg} / \mathrm{kg}$ body weight. While being viewed under a surgical microscope (Carl Zeiss, Mainz, Germany), a groin incision was made. The femoral artery was clamped temporarily at the level of the inguinal ligament, and an arteriotomy was made distal to the epigastric branch. The guidewire was then inserted, the clamp removed, the wire advanced to the level of the aortic bifurcation, and the balloon inflated. After removal of the wire, the arteriotomy site was ligated. Injured arteries were harvested 4 weeks after balloon dilation.

2.7. Histology and Immunohistochemistry. Specimens were perfused-fixed with $4 \%$ paraformaldehyde in PBS at $100 \mathrm{mmHg}$ for 15 minutes followed by excision of the femoral artery. Specimens were fixed overnight in $4 \%$ paraformaldehyde in PBS and decalcified in 1\% formic acid. Two $2 \mathrm{~mm}$ thick transverse segments were cut from each artery at the level of injury in the femoral artery and processed for paraffin embedding. Five micrometer sections were cut and stained with Masson's trichrome and hematoxylin-eosin. Human arterial tissue was obtained from patients who underwent vascular surgery. For immunohistochemistry, tissue sections were deparaffinized, rehydrated, and heated in a microwave for 10 minutes in citrate buffer. The tissue sections were then incubated with primary antibodies for 16 hours at $4^{\circ} \mathrm{C}$. Immunohistochemistry was performed using a Polink-1 HRP Rat-NM DAB Detection System (GBI Inc., WA, USA). 


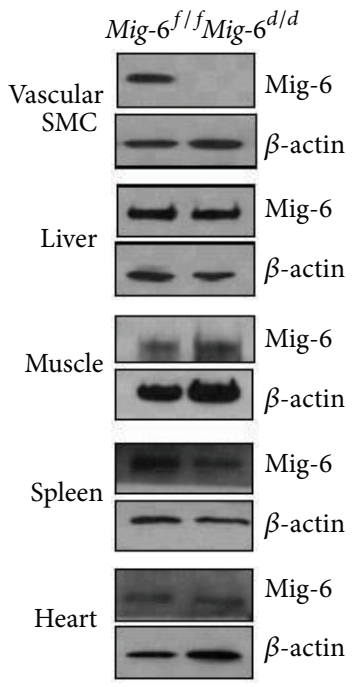

(a)
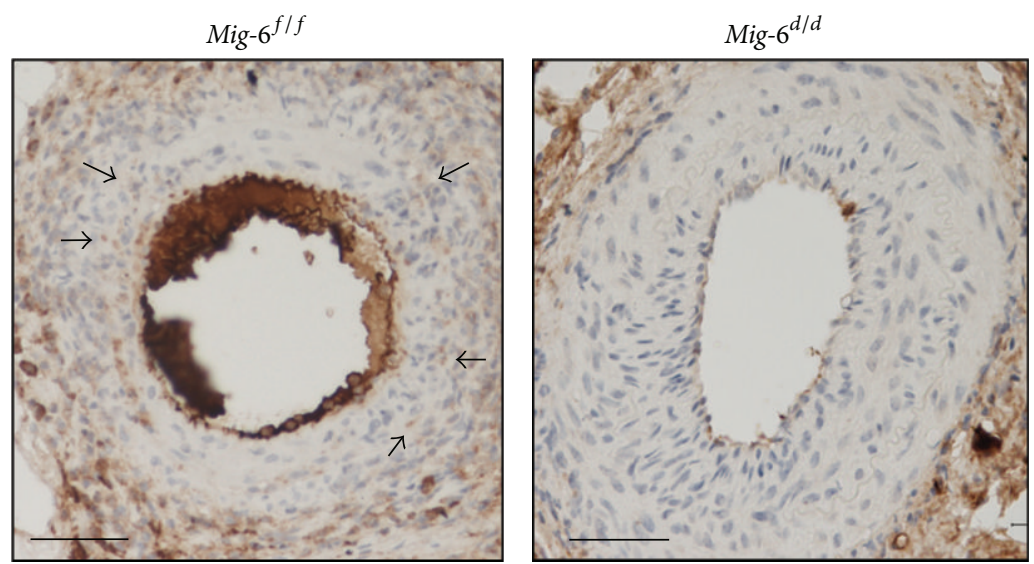

(b)

FIGURE 1: Generation of vascular smooth muscle specific Mig-6 knockout mice. (a) Western blotting of Mig-6 protein in the various tissues of Mig- $6^{f / f}$ and Mig- $6^{d / d}$ mice. (b) Mig-6 expression (arrow) was identified by immunohistochemistry in the femoral artery of Mig- $6^{f / f}$ and Mig- $6^{d / d}$ mice. Scale bar, $100 \mu \mathrm{m}$.

2.8. Western Blot Analysis. Total protein from cultured cells or mouse tissues was extracted in lysis buffer and separated using SDS-PAGE. The separated proteins were transferred to a nitrocellulose (NS) membrane (Amersham Biosciences, Freiburg, Germany). Membranes were blocked with 5\% skim milk in TBS and incubated with primary antibodies overnight at $4^{\circ} \mathrm{C}$ followed by secondary antibodies for 1 hour at room temperature. Immunoreactive bands were developed using ECL reagents. To control for loading, the membrane was stripped and reprobed with mouse-anti- $\beta$-actin antibody (Sigma-Aldrich, St. Louis, USA). Primary antibodies against mouse Mig-6, phosphorylated EGFR, total EGFR, phosphorylated AKT, total AKT, phosphorylated ERK, and total ERK were purchased from Cell Signaling (Danvers, Massachusetts, USA). The anti- $\alpha$-smooth muscle actin antibody was obtained from Boster Biological Technology (Oxfordshire, UK). Secondary antibodies (goat anti-mouse and goat anti-rabbit) were obtained from Cell Signaling.

2.9. Statistical Analyses. Data are presented as means \pm or + standard error (SE). Statistical significance for comparisons was determined using Student's two-tailed $t$-test. A $P$ value less than 0.05 was considered statistically significant.

\section{Results}

3.1. Generation of Mig-6 Conditional Knockout Vascular Smooth Muscle Using Tagln ${ }^{\text {Cre }}$. In order to investigate the role of Mig-6 in vascular SMCs, we generated vascular SMCspecific Mig-6 conditional knockout mice. We crossed floxed Mig-6 mice $\left(M i g-\sigma^{f / f}\right)$ with mice expressing a Cre recombinase gene under the control of the transgelin promoter $\left(\right.$ Tagln ${ }^{\text {Cre }}$ Mig- $^{f / f} ;$ Mig- $\left.^{d / d}\right)$. Smooth muscle specific conditional Mig- 6 ablation was confirmed by Western blot analysis of Mig-6 protein levels in primary cultures of vascular SMCs and in whole liver, skeletal muscle, spleen, and heart. Protein expression was specifically decreased in the vascular SMCs of Mig- $6^{d / d}$ mice compared with Mig- $6^{f / f}$ mice (Figure 1(a)). However, we did not observe differences in the expression levels in the liver, skeletal muscle, spleen, or heart between Mig- $6^{f / f}$ and Mig- $6^{d / d}$ mice. Immunohistochemistry confirmed that the expression of Mig- 6 was decreased in the vascular smooth muscle of Mig- $6^{d / d}$ mice (Figure 1(b)).

\subsection{Tagln ${ }^{\text {Cre }}$ Mig-6 Knockout Mice Display Enhanced Neoin-} tima Formation after Femoral Arterial Injury. To ascertain the role of Mig-6 in the development of atherosclerosis, morphological analysis was performed on the femoral artery of Mig- $6^{d / d}$ and Mig- $6^{f / f}$ mice following vascular injury. We provided endoluminal injury to one side of the femoral artery using balloon dilatation in Mig- $6^{d / d}$ and Mig- $6^{f / f}$ mice. Four weeks after injury, both injured and uninjured arteries were dissected and stained with hematoxylin-eosin and Masson's trichrome. No difference in morphology was noted in the uninjured arteries (data not shown). However, the injured arteries of $\mathrm{Mig}-6^{\mathrm{d} / \mathrm{d}}$ mice demonstrated an increased neointimal area (Figure 2(a)). This corresponded to a 5.3fold increase in the neointima/media ratio of $M i g-6^{d / d}(n=$ 6) compared with Mig- $6^{f / f}(n=7)$ vessels $(P=0.04)$ (Figure 2(b)).

\subsection{EGFR Phosphorylation Was Increased in Mig-6 Knockout} Vascular SMCs. MIG-6 is a known inhibitor of EGFR [14, 15, 29]. To investigate the role of EGFR signaling in the enhanced neointima formation of Mig- $6^{d / d}$ mice, vascular SMCs were isolated from the aortas of Mig- $6^{d / d}$ and Mig- $6^{f / f}$ mice. 


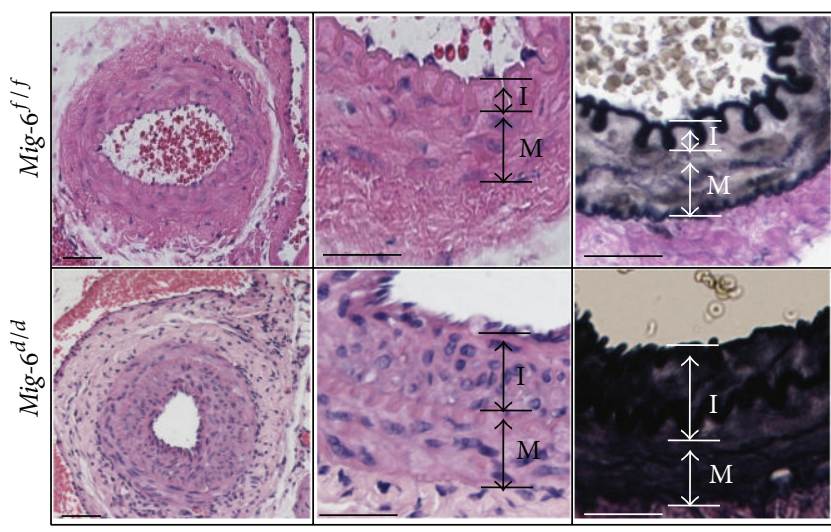

(a)

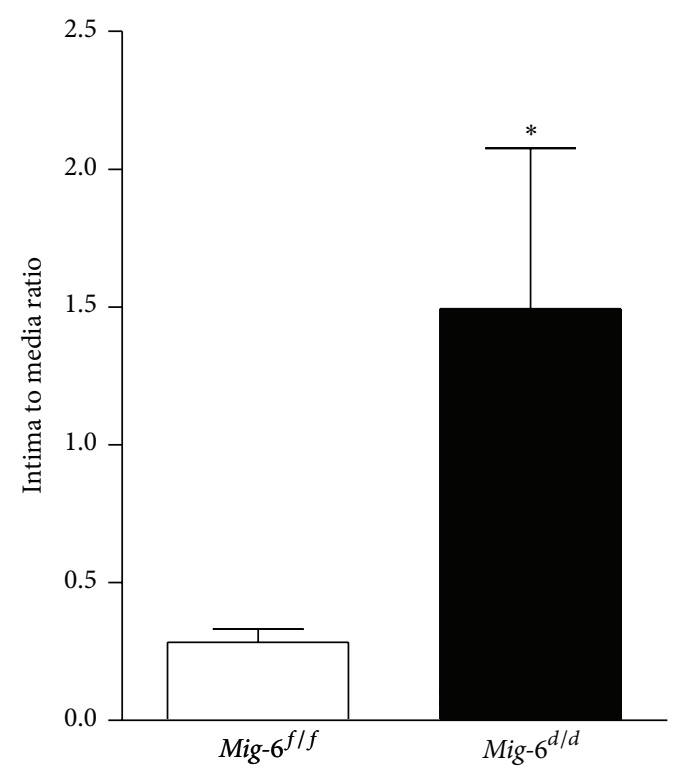

(b)

FIGURE 2: Neointima formation is increased in the vascular smooth muscle specific Mig-6 knockout mice. (a) Representative cross sections of balloon-catheter injured femoral artery. Left column, hematoxylin and eosin stain $\times 200$; middle column, hematoxylin and eosin stain $\times 400$; right column, Masson's trichrome stain $\times 400$. I, intima; $\mathrm{M}$, media; scale bar, $50 \mu \mathrm{m}$. (b) Quantification of intima to media ratio. $n=6$ for Mig- $6^{f / f}$ mice; $n=7$ for Mig- $6^{d / d}$ mice. ${ }^{*} P<0.05$.

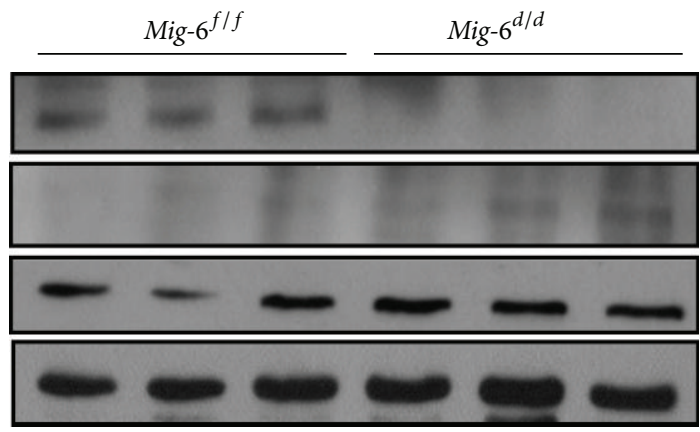

(a)

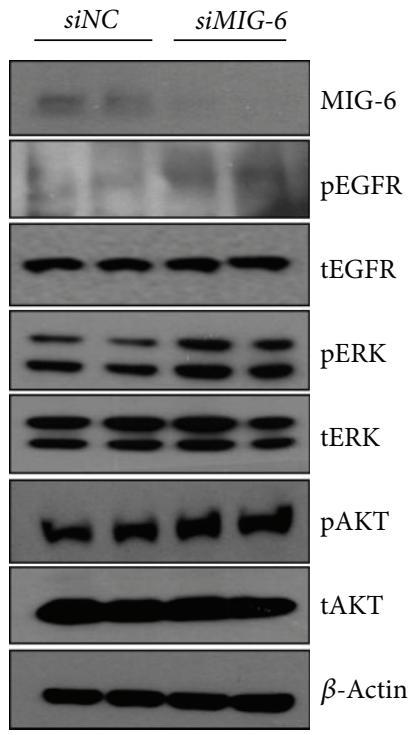

(b)

FIGURE 3: EGFR phosphorylation of vascular SMCs with regard to Mig-6 knockout. (a) Western blotting for phospho-EGFR in cultured vascular SMCs of Mig- $6^{d / d}$ and Mig- $6^{f / f}$ mice. pEGFR, phospho-EGFR; $\alpha$ SMA, $\alpha$-smooth muscle actin. (b) Western blotting for EGFR and downstream signals according to transfection of siRNA into human vascular SMCs. siNS, transfection of nonspecific siRNA; siMIG-6, transfection of siRNAs against MIG-6; pEGFR, phospho-EGFR; tEGFR, total EGFR; pERK, phospho-ERK; tERK, total ERK; pAAK, phosphoAkt; tAKT, total AKT.

We observed no difference in total EGFR levels in cultured vascular SMCs from Mig- $6^{d / d}$ versus Mig- $6^{f / f}$ mice by Western blot. However, phosphorylation of EGFR was increased in Mig- $6^{d / d}$ mice compared with Mig- $6^{f / f}$ mice (Figure 3(a)). Therefore, as expected, activation of EGFR signaling in vascular SMCs is implicated in enhanced neointima formation observed in Mig-6 knockout mice. To further explore the effects of Mig- 6 ablation on EGFR signaling in human vascular SMCs, we transfected siRNAs against Mig-6 into human vascular SMCs. Mig-6 knockdown in human vascular 
SMCs resulted in increased phosphorylation of EGFR and EGFR downstream signaling molecules, including ERK and AKT (Figure 3(b)).

3.4. Migration and Proliferation Were Increased in Cultured Vascular SMCs from Mig-6 Knockout Mice. A key element in the development of the neointima is the proliferation of intimal SMCs and migration of SMCs from the vessel media to the intima [3]. To determine whether enhanced SMC proliferation and migration also occur in vitro, we investigated the behavior of cultured vascular SMCs from $M i g-6^{d / d}$ and Mig- $6^{f / f}$ mice. First, we examined the migration of SMCs in response to various chemotactic agents. Vascular SMCs from Mig- $6^{d / d}$ mice demonstrated a 2.5 -fold increase in migration compared with the cells from Mig- $6^{f / f}$ mice $(P<$ 0.001 ) (Figure $4(\mathrm{a})$ ). In the presence of epidermal growth factor (EGF), vascular SMCs from both Mig- $6^{f / f}$ and Mig- $6^{d / d}$ mice demonstrated enhanced migration (1.7-fold, $P=0.031$, and 1.3-fold, $P<0.001$, resp.). Therefore, EGF provided an additive effect on cell migration in the Mig- $6^{d / d}$ vascular SMCs. EGFR transactivation through $G$ protein-coupled receptors by angiotensin II has also been demonstrated [3032]. In cultured vascular SMCs, angiotensin II increased migration of $\mathrm{Mig}^{-6^{d / d}}$ vascular SMCs additively. On the other hand, treatment with AG1478, an EGFR inhibitor, and angiotensin receptor blocker (ARB) abrogated this additive effect in Mig- $6^{d / d}$ vascular SMCs (Figure 4(b)).

In addition to enhanced migratory potential, the Mig6 knockout vascular SMCs displayed a 1.5-fold increase in proliferation compared with wild-type cells $(P<0.001)$ (Figure 4(c)). The enhanced proliferation was observed in the presence of EGF and also angiotensin II in Mig- $6^{d / d}$ vascular SMCs. Conversely, treatment of AG1478 did not reduce proliferation of Mig- $6^{d / d}$ vascular SMCs compared with untreated cells (Figure 4(d)).

3.5. Migration and Proliferation Were Increased in Mig-6 Knockout Human Vascular SMCs. To ascertain the role of MIG-6 in cell migration and proliferation in human vascular SMCs, we also performed migration and proliferation assays in siRNA-mediated Mig-6 knockdown human vascular SMCs. Mig-6 knockdown in human vascular SMCs also demonstrated an increase in migration and proliferation compared with wild-type cells (1.9-fold, $P<0.001$, and 1.5fold, $P<0.001$, resp.) (Figures 5(a) and 5(c)). Treatment of angiotensin II significantly increased migration in Mig6 knockout human vascular SMCs (Figure 5(a)). Separate treatment with either EGF or angiotensin II significantly increased proliferation in Mig-6-ablated human vascular SMCs (Figure 5(c)). However, treatment with AG1478 or ARB led to decreases in migration and proliferation compared with untreated cells in Mig-6 knockout human vascular SMCs (Figures 5(b) and 5(d)). Despite the low level of detection of MIG-6 in human vascular SMCs (Figure 3(b)), suggestive of incomplete knockout of Mig-6, vascular SMCs exhibited a significant increase in migration, comparable to that of primary cultured vascular SMCs. This indicated that sufficient functional Mig- 6 knockdown had been achieved by siRNA transfection in the vascular SMCs.

\section{Discussion}

All four members of the EGFR family and most of the EGFlike ligands are expressed in vascular smooth muscle cells [33]. Early evidence for a direct role of EGFR in vascular SMC activation was provided by studies in which treatment with EGF promoted bovine vascular SMC proliferation [25]. EGFR has also been demonstrated to mediate both cell proliferation and DNA synthesis in cultured rat aortic smooth muscle cells $[23,24]$. More recently, EGFR was found to play an important role in vascular SMC survival and matrix homeostasis using mice with an EGFR-targeted deletion [34].

Herein we investigated the role of EGFR in the proliferation and migration of vascular SMCs by ablating Mig-6 in both primary cultured murine SMCs and human vascular SMCs. Loss of Mig-6 enhanced vascular SMC migration, and this effect was inhibited by the addition of either AG1478 or ARB. However, while a loss of Mig-6 enhanced vascular SMC proliferation, AG1478 and ARB did not produce a biologically significant inhibition. A potential explanation for this observation is that AG1478 may have been administered at a suboptimal dose $(250 \mathrm{nM})$. In other cell lines, particularly tumor cells, higher doses are typically used [35-38]. However, based on other studies using vascular SMCs, $250 \mathrm{nM}$ is considered sufficient [39-41]. Therefore, in summary, increased migration in Mig-6 knockout vascular SMCs is mediated by EGFR activation. However, increased cellular proliferation appears to be induced directly by the loss of Mig-6, although we could not clarify the exact underlying mechanism.

To date, a limited number of studies have examined the role of EGFR in the development of atherosclerosis, despite the expression of EGFR in intimal SMCs within human atherosclerotic plaques [42]. Betacellulin, a member of the EGF family, has also been detected in both intimal and medial SMCs of the aortic wall by immunohistochemical staining. Numerous betacellulin-positive SMCs surrounding the core lesion of atherosclerotic plaques have been observed [42]. Epiregulin, another ligand of EGFR, is also detectable in human atherosclerotic arteries [43]. With regard to restenosis, some promising lines of evidence are being explored in animal models currently. Monoclonal blocking antibodies against EGFR inhibited medial SMC proliferation and intimal hyperplasia in balloon-injured rat carotid arteries [44]. Moreover, periadventitial delivery of an EGFR-blocking monoclonal antibody inhibited neointimal macrophage accumulation and neointimal thickening after balloon-catheter angioplasty in a hypercholesterolemic rabbit [45].

In this study, we demonstrated the role of EGFR signaling in the development of atherosclerosis and restenosis in vivo, using Mig- 6 conditional-knockout mice. Vascular SMCs from Mig-6 knockout mice demonstrated an increase in EGFR phosphorylation and EGFR downstream signaling. Balloon-injured arteries of Mig-6 knockout mice presented 

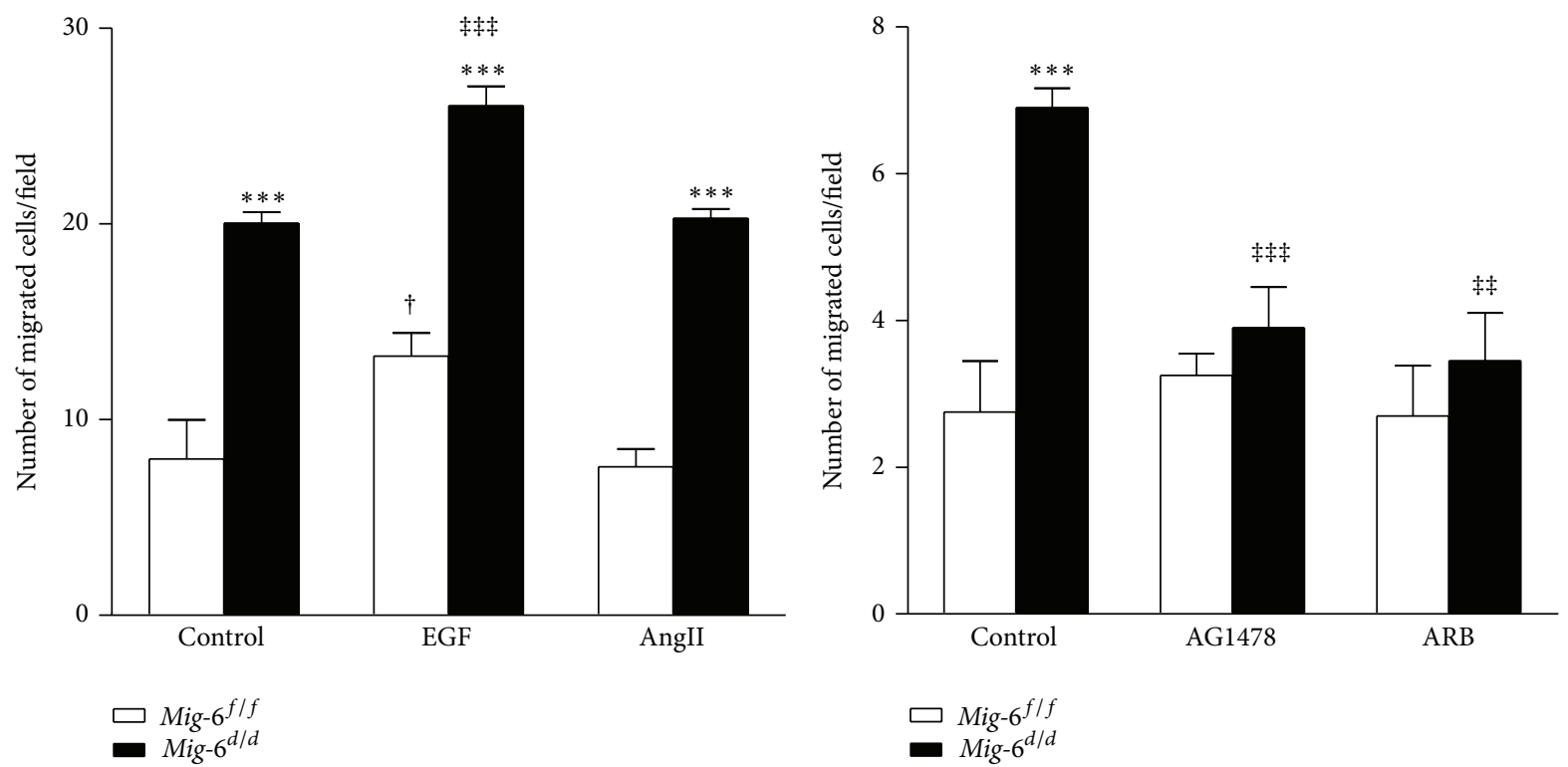

(a)

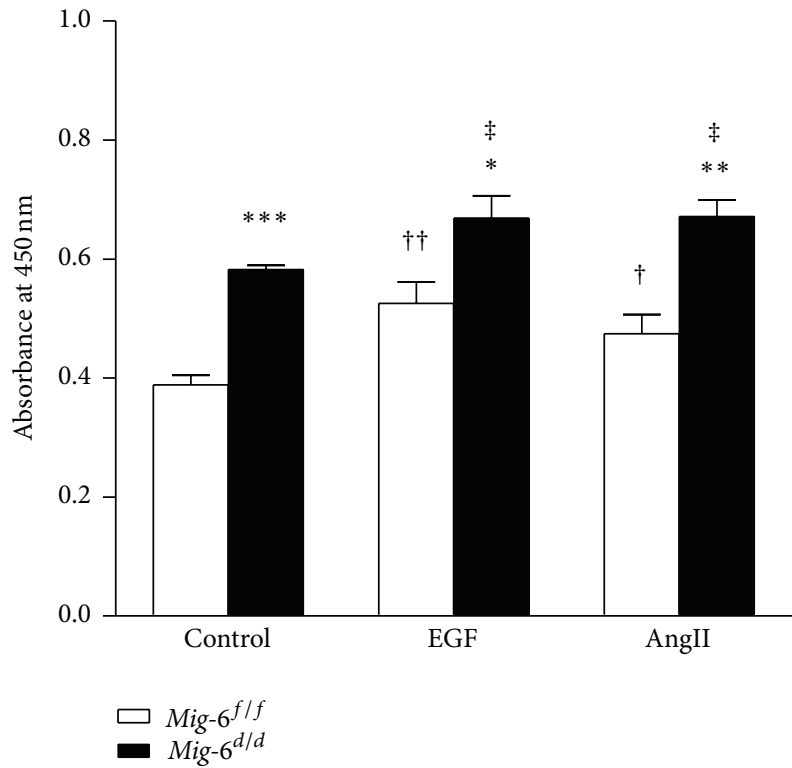

(c) (b)

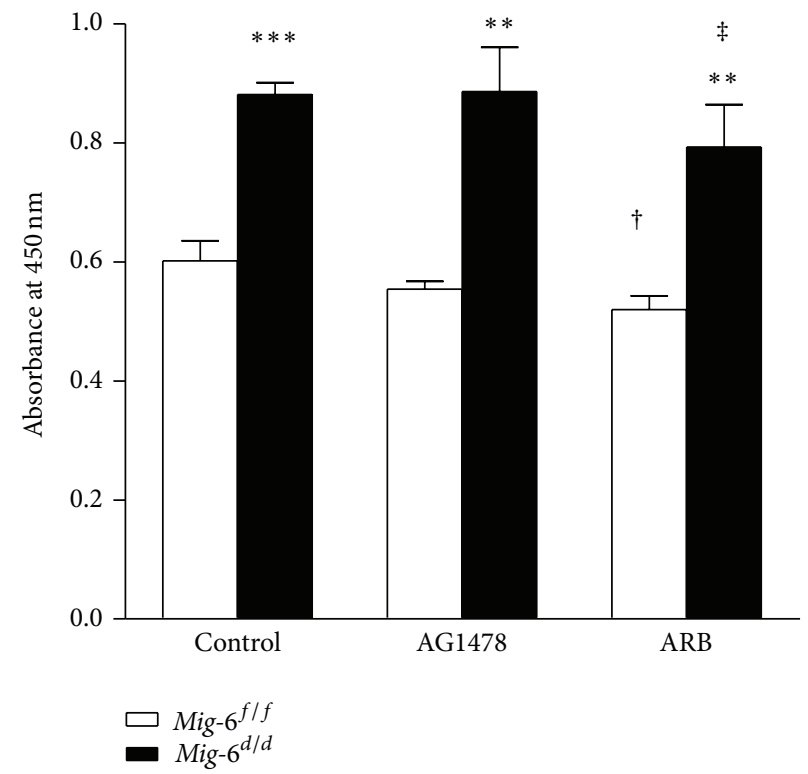

(d)

FIGURE 4: Migration and proliferation of primary cultured vascular SMCs from Mig- $6^{d / d}$ and Mig- $6^{f / f}$ mice. (a) Changes of cell migration in response to EGFR activators. (b) Changes of cell migration in response to EGFR inhibitors. (c) Changes of cell proliferation in response to EGFR activators. (d) Changes of cell proliferation in response to EGFR inhibitors. $n=4,10 \sim 12$-week-old male mice. EGF $10 \mathrm{ng} / \mathrm{mL}$, AngII $100 \mathrm{mM}$, AG1478I $250 \mathrm{nM}$, and ARB $100 \mu \mathrm{M}$. EGF, epidermal growth factor; AngII, angiotensin II; ARB, angiotensin receptor blocker. ${ }^{*} P<0.05,{ }^{* *} P<0.01$, and ${ }^{* * *} P<0.001$ versus Mig- $6{ }^{f / f} ;{ }^{\dagger} P<0.05$ and ${ }^{\dagger \dagger} P<0.01$ versus Mig- 6 f/f control; ${ }^{\ddagger} P<0.05$, ${ }^{\ddagger \ddagger} P<0.01$, and ${ }^{\ddagger} P<0.001$ versus Mig- $6^{d / d}$ control.

with increased neointimal area, while there were no significant changes observed in the morphology of uninjured arteries. In this report, we did not confirm the role of EGFR in excessive neointima formation using pharmacological EGFR blocking agents, such as Erlotinib, Lapationib, or Irresa, in vivo. Therefore, the excessive neointima formation could be induced by Mig-6 loss itself, as we noted previously. Similarly, there are also reports on the phenotypes of the breast and endometrium associated with a loss of Mig- 6 but unrelated to excessive EGFR signaling $[46,47]$.

Percutaneous coronary intervention using stenting is widely performed in the treatment of symptomatic coronary disease. Nevertheless, serious concerns exist regarding late complications, such as in-stent restenosis and late stent thrombosis. Although drug-eluting stents have minimized the limitations of bare-metal stents, clinical and histologic 

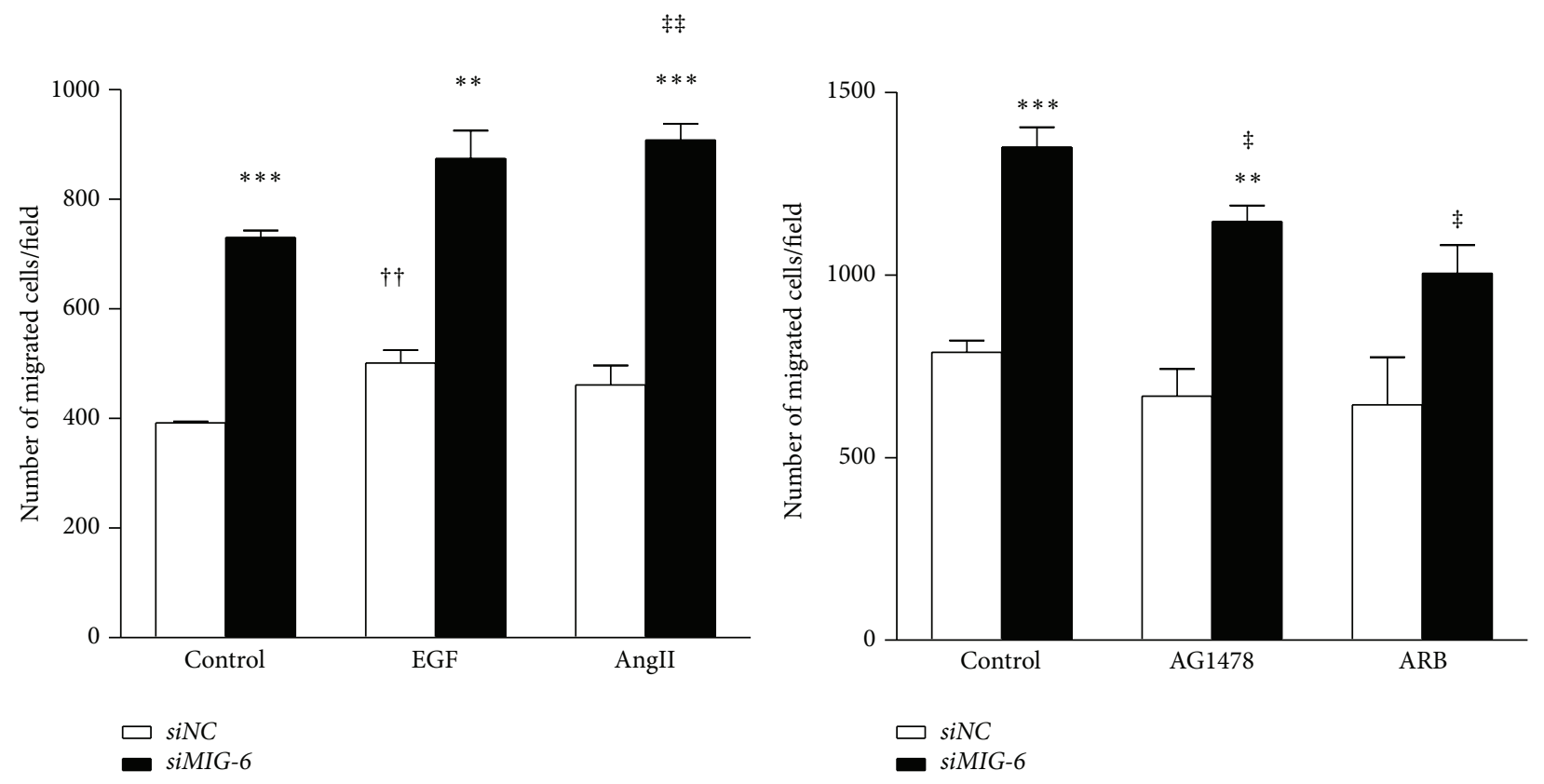

(a)
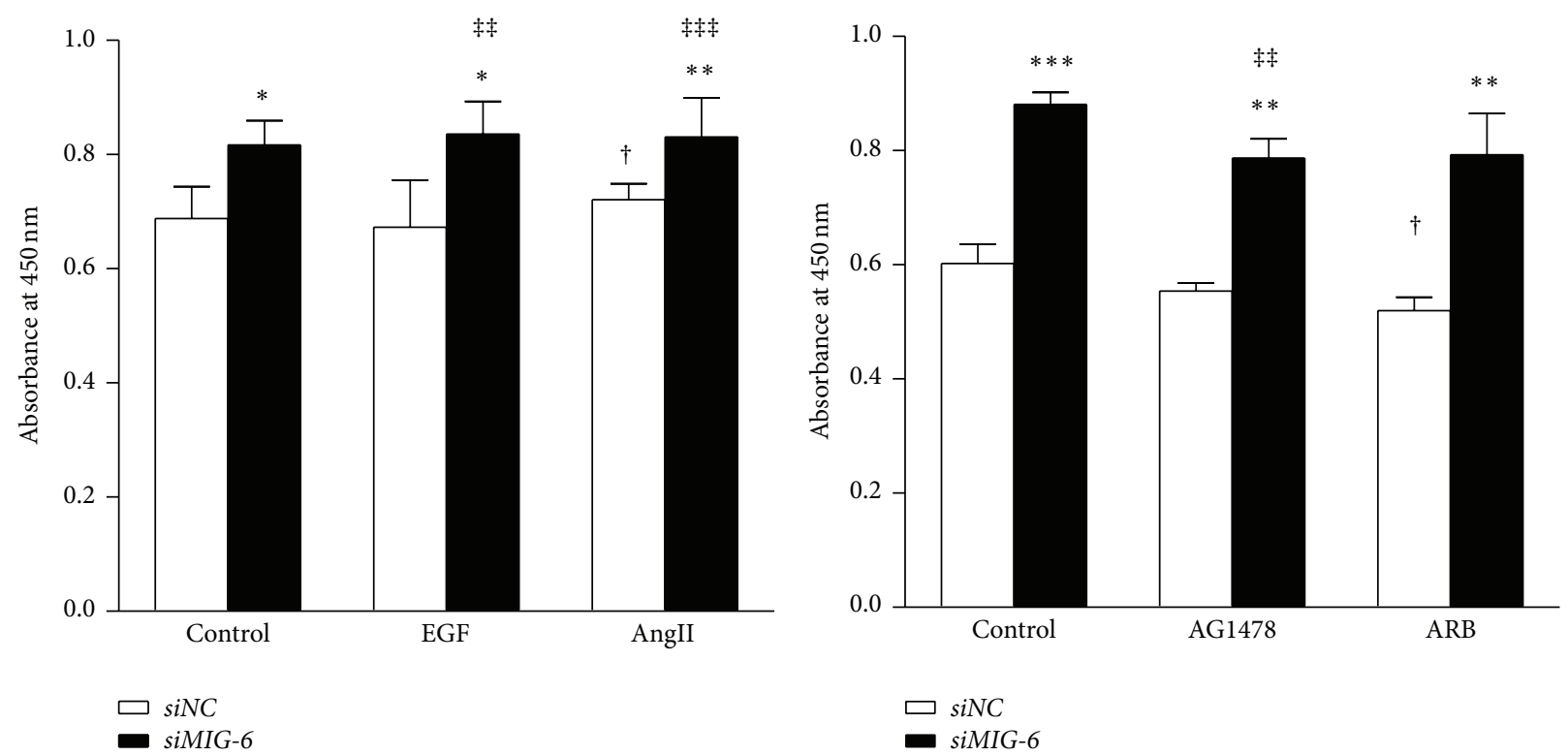

(c)

(d)

FIGURE 5: Migration and proliferation of MIG-6-silenced human vascular SMCs. (a) Changes of cell migration in response to EGFR activators. (b) Changes of cell migration in response to EGFR inhibitors. (c) Changes of cell proliferation in response to EGFR activators. (d) Changes of cell proliferation in response to EGFR inhibitors. EGF $10 \mathrm{ng} / \mathrm{mL}$, AngII $100 \mathrm{mM}$, AG1478I $250 \mathrm{nM}$, and ARB $100 \mu \mathrm{M}$. EGF, epidermal growth factor; AngII, angiotensin II; ARB, angiotensin receptor blocker. ${ }^{*} P<0.05,{ }^{* *} P<0.01$, and ${ }^{* * *} P<0.001$ versus $M i g-6 / f$; ${ }^{\dagger} P<0.05$ and ${ }^{\dagger \dagger} P<0.01$ versus Mig- $6 / f$ control; ${ }^{\ddagger} P<0.05$, ${ }^{\ddagger \ddagger} P<0.01$, and ${ }^{\ddagger \ddagger} P<0.001$ versus Mig- $6{ }^{d / d}$ control.

studies have demonstrated evidence of continuous neointimal growth during long-term follow-up [40]. The precise mechanisms of neoatherosclerosis development with drugeluting stents remain unclear to date. Our results demonstrate a potential role for Mig-6 or EGFR signaling in the development of neoatherosclerosis and could represent a novel pathway contributing to disease. Previously, we performed
Mig-6 conditional knockout in the liver using the albuminCre mouse model [22]. These mice exhibited increased serum levels of low density lipoprotein cholesterol. The genes that regulate lipid metabolism, bile acid, and cholesterol synthesis were also altered in the liver. Taking these two studies together, Mig- 6 clearly plays an important role in the development of atherosclerosis. 
In conclusion, we have found that smooth muscle cellspecific ablation of Mig-6 induced neointimal hyperplasia after balloon injury in the mouse model. In addition, Mig6 knockout in vascular SMCs demonstrated increases in cell migration and proliferation potential. To our knowledge, this is the first report of Mig-6 involvement in the vascular biology of atherosclerosis. Furthermore, this represents a potentially novel mechanism to explain neointimal hyperplasia. This information will provide new insight into aiding the development of more effective strategies to treat and prevent atherosclerosis, specifically in-stent restenosis after percutaneous vascular intervention.

\section{Conflict of Interests}

The authors declare that there is no conflict of interests regarding the publication of this paper.

\section{Acknowledgments}

This work was supported by 2009 Korean Diabetes Association Research Grant and the National Research Foundation of Korea (NRF) grant funded by the Korean Government NRF2013R1A1A2004719.

\section{References}

[1] G. D. Dangas, B. E. Claessen, A. Caixeta, E. A. Sanidas, G. S. Mintz, and R. Mehran, "In-stent restenosis in the drug-eluting stent era," Journal of the American College of Cardiology, vol. 56, no. 23, pp. 1897-1907, 2010.

[2] P. Libby, P. M. Ridker, and G. K. Hansson, "Progress and challenges in translating the biology of atherosclerosis," Nature, vol. 473, no. 7347, pp. 317-325, 2011.

[3] P. Pauletto, S. Sartore, and A. C. Pessina, "Smooth-muscle-cell proliferation and differentiation in neointima formation and vascular restenosis," Clinical Science, vol. 87, no. 5, pp. 467-479, 1994.

[4] C. Bauters and J. M. Isner, “The biology of restenosis," Progress in Cardiovascular Diseases, vol. 40, no. 2, pp. 107-116, 1997.

[5] W. S. Weintraub, "The pathophysiology and burden of restenosis," The American Journal of Cardiology, vol. 100, no. 5, pp. S3S9, 2007.

[6] J. H. Ip, V. Fuster, L. Badimon, J. Badimon, M. B. Taubman, and J. H. Chesebro, "Syndromes of accelerated atherosclerosis: role of vascular injury and smooth muscle cell proliferation," Journal of the American College of Cardiology, vol. 15, no. 7, pp. 1667-1687, 1990.

[7] W. Casscells, "Migration of smooth muscle and endothelial cells: critical events in restenosis," Circulation, vol. 86, no. 3, pp. 723-729, 1992.

[8] A. K. Mitra and D. K. Agrawal, "In stent restenosis: bane of the stent era," Journal of Clinical Pathology, vol. 59, no. 3, pp. 232239, 2006.

[9] A. Makkinje, D. A. Quinn, A. Chen et al., "Gene 33/mig-6, a transcriptionally inducible adapter protein that binds GTPCdc42 and activates SAPK/JNK. A potential marker transcript for chronic pathologic conditions, such as diabetic nephropathy. Possible role in the response to persistent stress," The Journal of Biological Chemistry, vol. 275, no. 23, pp. 17838-17847, 2000.
[10] L. Fiorentino, C. Pertica, M. Fiorini et al., "Inhibition of ErbB2 mitogenic and transforming activity by RALT, a mitogeninduced signal transducer which binds to the ErbB-2 kinase domain," Molecular and Cellular Biology, vol. 20, no. 20, pp. 7735-7750, 2000.

[11] T. Tsunoda, J. Inokuchi, I. Baba et al., "A novel mechanism of nuclear factor $\kappa \mathrm{B}$ activation through the binding between inhibitor of nuclear factor- $\kappa \mathrm{B} \alpha$ and the processed NH2terminal region of Mig-6," Cancer Research, vol. 62, no. 20, pp. 5668-5671, 2002.

[12] Y.-W. Zhang and G. F. V. Woude, "Mig-6, signal transduction, stress response and cancer," Cell Cycle, vol. 6, no. 5, pp. 507-513, 2007.

[13] S. Anastasi, L. Fiorentino, M. Fiorini et al., "Feedback inhibition by RALT controls signal output by the ErbB network," Oncogene, vol. 22, no. 27, pp. 4221-4234, 2003.

[14] D. Xu, A. Makkinje, and J. M. Kyriakis, "Gene 33 is an endogenous inhibitor of Epidermal Growth Factor (EGF) receptor signaling and mediates dexamethasone-induced suppression of EGF function," The Journal of Biological Chemistry, vol. 280, no. 4, pp. 2924-2933, 2005.

[15] X. Zhang, K. A. Pickin, R. Bose, N. Jura, P. A. Cole, and J. Kuriyan, "Inhibition of the EGF receptor by binding of MIG6 to an activating kinase domain interface," Nature, vol. 450, no. 7170, pp. 741-744, 2007.

[16] Y.-W. Zhang, B. Staal, Y. Su et al., "Evidence that MIG-6 is a tumor-suppressor gene," Oncogene, vol. 26, no. 2, pp. 269-276, 2007.

[17] S. Anastasi, G. Sala, C. Huiping et al., "Loss of RALT/MIG6 expression in ERBB2-amplified breast carcinomas enhances ErbB-2 oncogenic potency and favors resistance to Herceptin," Oncogene, vol. 24, no. 28, pp. 4540-4548, 2005.

[18] I. Ferby, M. Reschke, O. Kudlacek et al., "Mig6 is a negative regulator of EGF receptor-mediated skin morphogenesis and tumor formation," Nature Medicine, vol. 12, no. 5, pp. 568-573, 2006.

[19] T. H. Kim, H. L. Franco, S. Y. Jung et al., "The synergistic effect of Mig- 6 and Pten ablation on endometrial cancer development and progression," Oncogene, vol. 29, no. 26, pp. 3770-3780, 2010.

[20] C.-I. Lin, J. Du, W. T. Shen et al., "Mitogen-inducible gene-6 is a multifunctional adaptor protein with tumor suppressorlike activity in papillary thyroid cancer," The Journal of Clinical Endocrinology and Metabolism, vol. 96, no. 3, pp. E554-E565, 2011.

[21] T. H. Kim, D.-K. Lee, S.-N. Cho et al., "Critical tumor suppressor function mediated by epithelial mig-6 in endometrial cancer," Cancer Research, vol. 73, no. 16, pp. 5090-5099, 2013.

[22] B. J. Ku, T. H. Kim, J. H. Lee et al., "Mig-6 plays a critical role in the regulation of cholesterol homeostasis and bile acid synthesis," PLoS ONE, vol. 7, no. 8, Article ID e42915, 2012.

[23] M. Tomita, Y. Hirata, M. Uchihashi, and T. Fujita, "Characterization of epidermal growth factor receptors in cultured vascular smooth muscle cells of rat aorta," Endocrinologia Japonica, vol. 33, no. 2, pp. 177-184, 1986.

[24] L. B. Nanney, C. M. Stoscheck, and L. E. King, "Characterization of binding and receptors for epidermal growth factor in smooth muscle," Cell and Tissue Research, vol. 254, no. 1, pp. 125-132, 1988.

[25] D. Gospodarowicz, K. Hirabayashi, L. Giguere, and J. P. Tauber, "Factors controlling the proliferative rate, final cell density, and life span of bovine vascular smooth muscle cells in culture," The Journal of Cell Biology, vol. 89, no. 3, pp. 568-578, 1981. 
[26] J. Thyberg, U. Hedin, M. Sjolund, L. Palmberg, and B. A. Bottger, "Regulation of differentiated properties and proliferation of arterial smooth muscle cells," Arteriosclerosis, vol. 10, no. 6, pp. 966-990, 1990.

[27] S. Higashiyama, J. A. Abraham, and M. Klagsbrun, "Heparinbinding EGF-like growth factor stimulation of smooth muscle cell migration: dependence on interactions with cell surface heparan sulfate," The Journal of Cell Biology, vol. 122, no. 4, pp. 933-940, 1993.

[28] N. Jin, J. L. Gilbert, R. R. Broaddus, F. J. Demayo, and J.-W. Jeong, "Generation of a Mig- 6 conditional null allele," Genesis, vol. 45, no. 11, pp. 716-721, 2007.

[29] S. Anastasi, M. F. Baietti, Y. Frosi, S. Alemà, and O. Segatto, "The evolutionarily conserved EBR module of RALT/MIG6 mediates suppression of the EGFR catalytic activity," Oncogene, vol. 26, no. 57 , pp. 7833-7846, 2007.

[30] S. Higuchi, H. Ohtsu, H. Suzuki, H. Shirai, G. D. Frank, and S. Eguchi, "Angiotensin II signal transduction through the AT1 receptor: novel insights into mechanisms and pathophysiology," Clinical Science, vol. 112, no. 7-8, pp. 417-428, 2007.

[31] S. Eguchi, K. Numaguchi, H. Iwasaki et al., "Calcium-dependent epidermal growth factor receptor transactivation mediates the angiotensin II-induced mitogen-activated protein/kinase activation in vascular smooth muscle cells," The Journal of Biological Chemistry, vol. 273, no. 15, pp. 8890-8896, 1998.

[32] R. Kodali, M. Hajjou, A. B. Berman et al., "Chemokines induce matrix metalloproteinase-2 through activation of epidermal growth factor receptor in arterial smooth muscle cells," Cardiovascular Research, vol. 69, no. 3, pp. 706-715, 2006.

[33] N. Makki, K. W. Thiel, and F. J. Miller Jr., "The epidermal growth factor receptor and its ligands in cardiovascular disease," International Journal of Molecular Sciences, vol. 14, no. 10, pp. 20597-20613, 2013.

[34] B. Schreier, M. Döhler, S. Rabe et al., "Consequences of epidermal growth factor receptor (ErbB1) loss for vascular smooth muscle cells from mice with targeted deletion of ErbB1," Arteriosclerosis, Thrombosis, and Vascular Biology, vol. 31, no. 7, pp. 1643-1652, 2011.

[35] Y. Han, C. G. Caday, A. Nanda, W. K. Cavenee, and H.-J. S. Huang, "Tyrphostin AG 1478 preferentially inhibits human glioma cells expressing truncated rather than wild-type epidermal growth factor receptors," Cancer Research, vol. 56, no. 17, pp. 3859-3861, 1996.

[36] G. Partik, K. Hochegger, M. Schörkhuber, and B. Marian, "Inhibition of epidermal-growth-factor-receptor-dependent signalling by tyrphostins A25 and AG1478 blocks growth and induces apoptosis in colorectal tumor cells in vitro," Journal of Cancer Research and Clinical Oncology, vol. 125, no. 7, pp. 379-388, 1999.

[37] A. Shushan, N. Rojansky, N. Laufer et al., “The AG1478 tyrosine kinase inhibitor is an effective suppressor of leiomyoma cell growth," Human Reproduction, vol. 19, no. 9, pp. 1957-1967, 2004.

[38] Y.-G. Zhang, Q. Du, W.-G. Fang, M.-L. Jin, and X.-X. Tian, "Tyrphostin AG1478 supresses proliferation and invasion of human breast cancer cells," International Journal of Oncology, vol. 33, no. 3, pp. 595-602, 2008.

[39] S. Eguchi, K. Numaguchi, H. Iwasaki et al., "Calcium-dependent epidermal growth factor receptor transactivation mediates the angiotensin II-induced mitogen-activated protein/kinase activation in vascular smooth muscle cells," The Journal of Biological Chemistry, vol. 273, no. 15, pp. 8890-8896, 1998.
[40] H. Iwasaki, S. Eguchi, F. Marumo, and Y. Hirata, "Endothelin1 stimulates DNA synthesis of vascular smooth-muscle cells through transactivation of epidermal growth factor receptor," Journal of Cardiovascular Pharmacology, vol. 31, no. 1, pp. S182S184, 1998.

[41] D. Bokemeyer, U. Schmitz, and H. J. Kramer, "Angiotensin IIinduced growth of vascular smooth muscle cells requires an Srcdependent activation of the epidermal growth factor receptor," Kidney International, vol. 58, no. 2, pp. 549-558, 2000.

[42] R. Tamura, J.-I. Miyagawa, M. Nishida et al., "Immunohistochemical localization of Betacellulin, a member of epidermal growth factor family, in atherosclerotic plaques of human aorta," Atherosclerosis, vol. 155, no. 2, pp. 413-423, 2001.

[43] M. Takahashi, K. Hayashi, K. Yoshida et al., "Epiregulin as a major autocrine/paracrine factor released from ERK- and p38MAPK-activated vascular smooth muscle cells," Circulation, vol. 108, no. 20, pp. 2524-2529, 2003.

[44] A. K. Chan, A. Kalmes, S. Hawkins, G. Daum, and A. W. Clowes, "Blockade of the epidermal growth factor receptor decreases intimal hyperplasia in balloon-injured rat carotid artery," Journal of Vascular Surgery, vol. 37, no. 3, pp. 644-649, 2003.

[45] S. Shafi, D. Lamb, H. Modjtahedi, and G. Ferns, "Periadventitial delivery of anti-EGF receptor antibody inhibits neointimal macrophage accumulation after angioplasty in a hypercholesterolaemic rabbit," International Journal of Experimental Pathology, vol. 91, no. 3, pp. 224-234, 2010.

[46] S. Hopkins, E. Linderoth, O. Hantschel et al., "Mig6 is a sensor of EGF receptor inactivation that directly activates c-Abl to induce apoptosis during epithelial homeostasis," Developmental Cell, vol. 23, no. 3, pp. 547-559, 2012.

[47] J.-W. Jeong, S. L. Hee, K. Y. Lee et al., "Mig-6 modulates uterine steroid hormone responsiveness and exhibits altered expression in endometrial disease," Proceedings of the National Academy of Sciences of the United States of America, vol. 106, no. 21, pp. 86778682, 2009. 


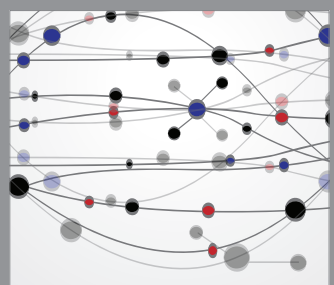

The Scientific World Journal
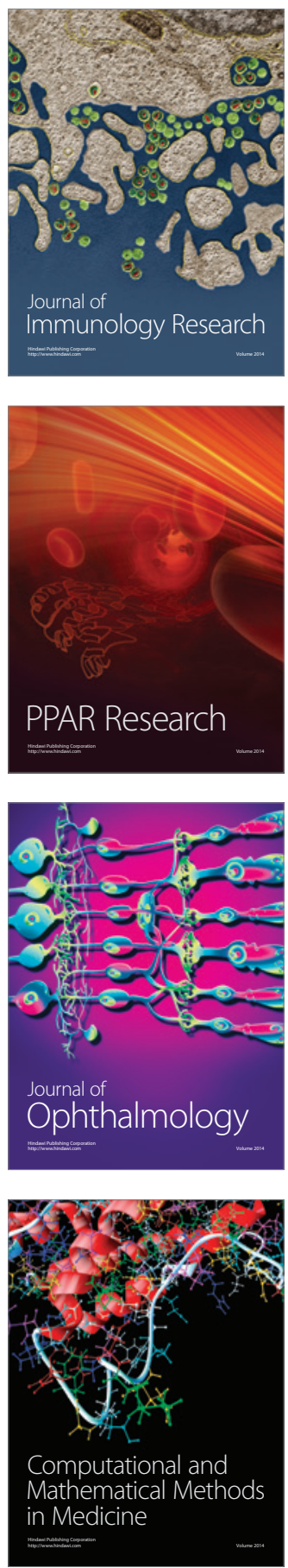

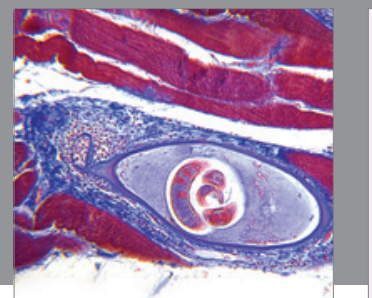

Gastroenterology

Research and Practice
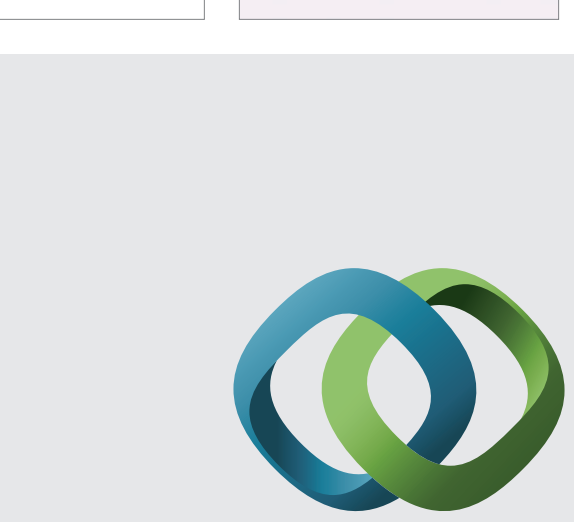

\section{Hindawi}

Submit your manuscripts at

http://www.hindawi.com
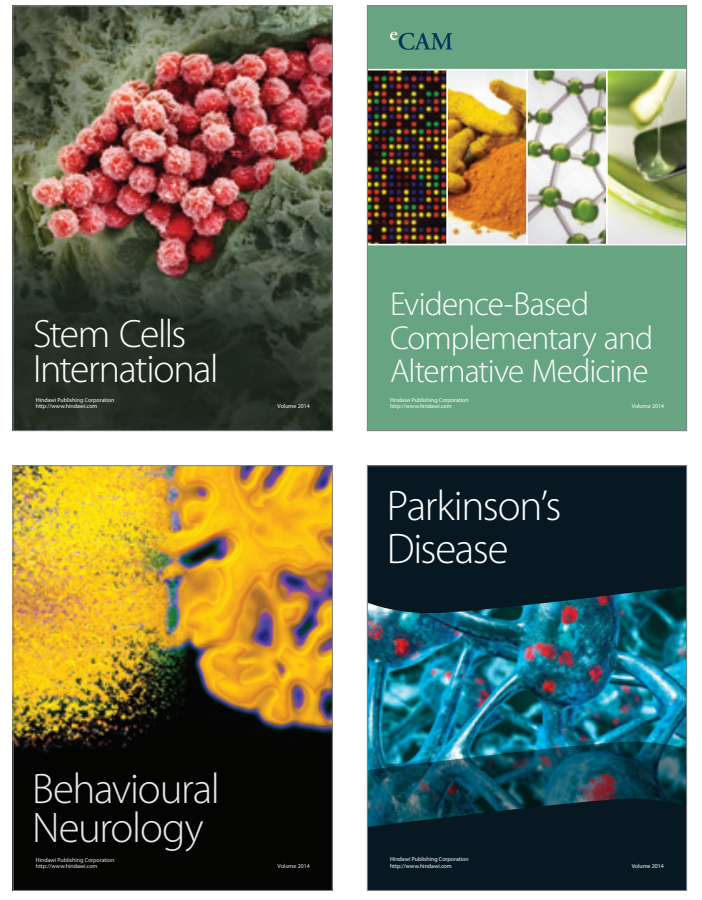
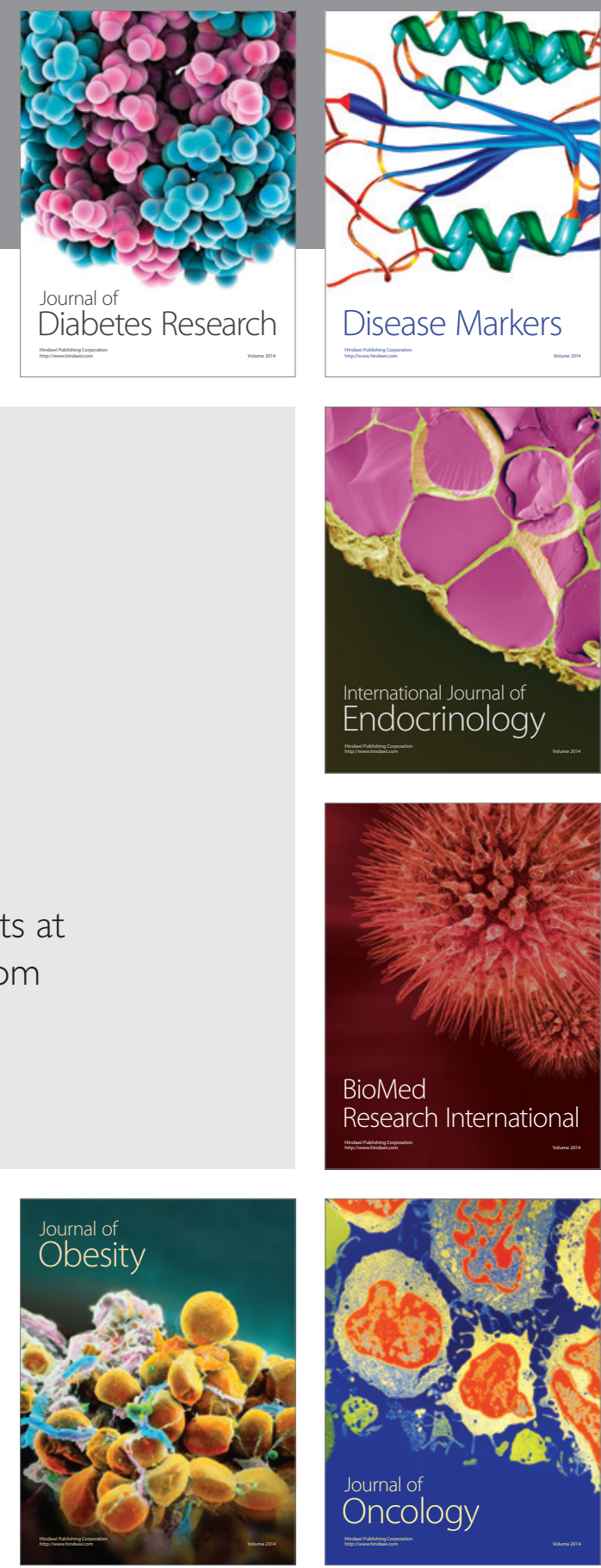

Disease Markers
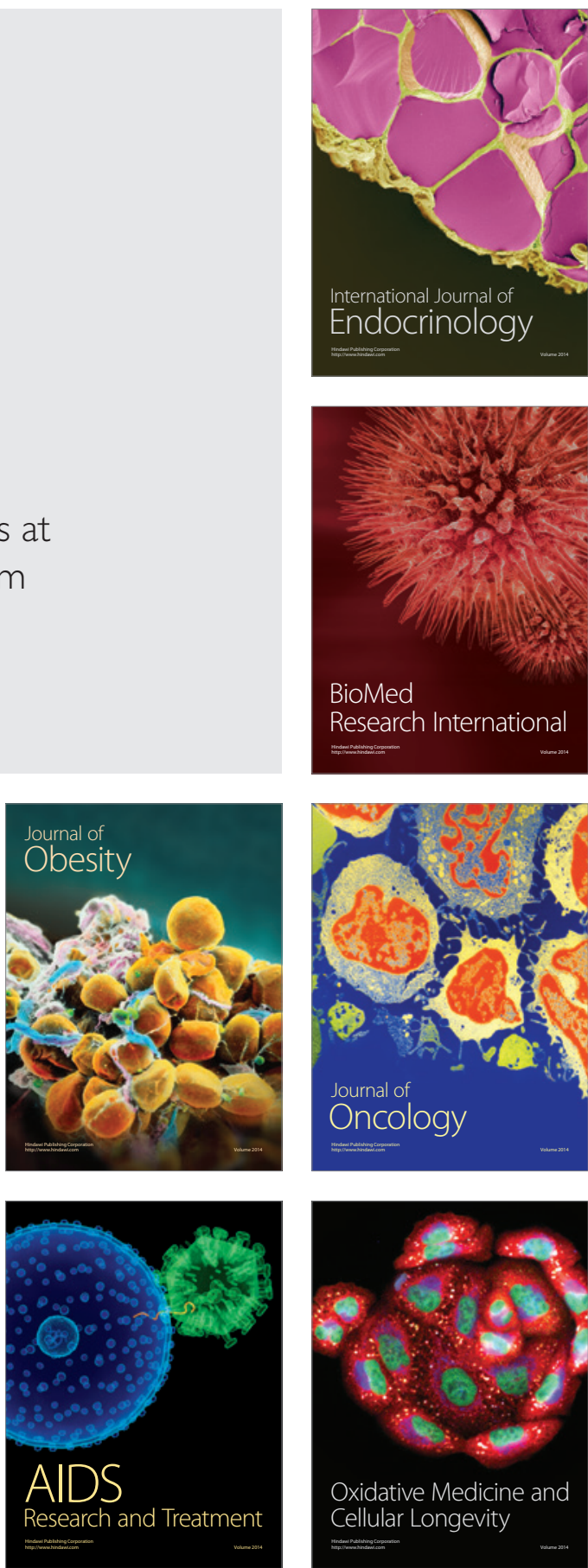